\title{
Modification of the Corrosion Properties of a Model Fe-8Ni-18Cr Steel Resulting from Plastic Deformation and Evaluated by Impedance Spectroscopy
}

\author{
Pierre-Yves Girardin, ${ }^{1}$ Adrien Frigerio, ${ }^{1}$ and Patrice Berthod ${ }^{2}$ \\ ${ }^{1}$ Lycée Henri Loritz, 29 Rue des Jardiniers, 54000 Nancy, France \\ ${ }^{2}$ Institut Jean Lamour, University of Lorraine, Boulevard des Aiguillettes, B.P. 70239, 54506 Vandoeuvre-lès-Nancy, France
}

Correspondence should be addressed to Patrice Berthod, patrice.berthod@ijl.nancy-universite.fr

Received 30 August 2012; Accepted 14 September 2012

Academic Editors: M. Aparicio, G. Marginean, Q. Qu, and C. Valentini

Copyright (C) 2012 Pierre-Yves Girardin et al. This is an open access article distributed under the Creative Commons Attribution License, which permits unrestricted use, distribution, and reproduction in any medium, provided the original work is properly cited.

\begin{abstract}
A model \{minor elements\}-free Fe-8Ni-18Cr alloy (wt\%) was elaborated by foundry, then cut in several cylindrical parts which were subjected to compression tests leading to different plastic deformation rates. The axis surface of the obtained samples were characterized in corrosion by impedance spectroscopy in an acid sulphuric solution. The obtained EIS results were plotted in the complex plan of Nyquist and the diagrams were all semicircular but with an average radius decreasing when the deformation rate increased. The plastic deformation obviously induced a decrease in charge transfer resistance, revealing a detrimental effect of the corrosion behaviour as the most often reported in studies involving stationary methods of electrochemical characterization of corrosion. It was also found that the capacitance tends to increase with the rate of plastic deformation by compression.
\end{abstract}

\section{Introduction}

A lot of fabrication processes induce for metals and alloys more or less severe plastic deformation for obtaining the required shapes for the pieces (e.g., cold or hot rolling, forging, stamping, etc.). Such permanent deformations, by multiplying defects and dislocations, can be responsible of significant changes in the mechanical properties as well as of modification of the surface reactivity. The effect of plastic deformation on the mechanical behaviour of the alloys is well known (e.g., increased hardness and elastic resistance) [1] but it is not really the same about the consequences on the corrosion behaviour since the observations are rather scattered on this subject. Indeed, numerous studies have been done in the past about the influence of mechanical deformation (e.g., cold-rolling) on the corrosion behaviour of metals and alloys (aluminium- [2], magnesium- [3], or titanium-based [4]), and also of stainless steels in various solutions [5-7]. If it was sometimes found that plastically deformed iron-based alloys are more resistant against aqueous corrosion than before deformation $[8,9]$ the contrary was more frequently observed, as reported in many works. Between all these earlier works the studied alloys were different from one another, concerning their fabrication details or their chemical compositions which contained or not elements able to influence the corrosion behaviour even if they are present in low quantities.

The aim of the present work is to study the effect of a plastic deformation of an alloy on its corrosion behaviour by avoiding some of the previous possible causes of results dispersion. A ternary alloy was elaborated by foundry, including a homogenization stage at high temperature long enough to be sure that the liquid is at the same composition everywhere before solidification, then an aspiration in a low-diameter tube to limit the chemical segregations during solidification. The cylindrical samples cut in this single ingot, then all of the same chemical composition, were subjected to compression at different deformation rates, then their corrosion behaviour characterized by impedance spectroscopy, a well-known experimental method [10] successfully used in this field for several of tens years, and for example recently used for steels [11-15] and other metals or alloys 


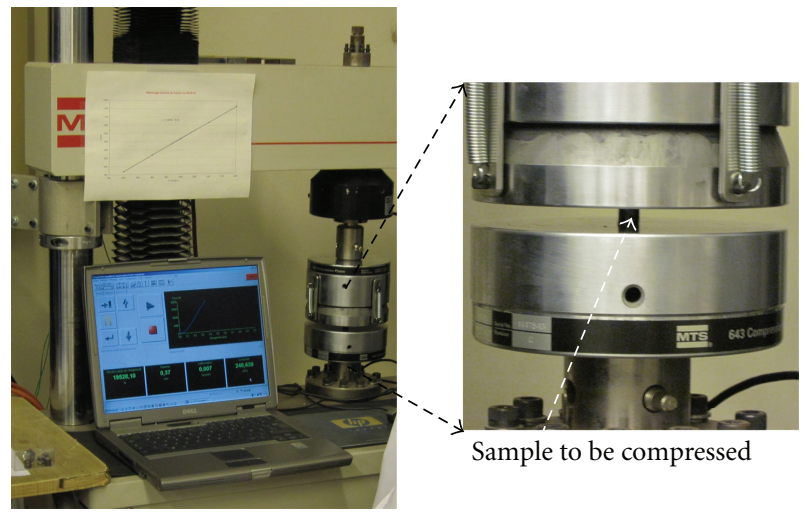

FIgURE 1: Photographs of the testing machine and of the platens ready to compress a sample.

(Cr and Zn coatings [16], copper [17], aluminium [18], bronzes [19], etc.).

\section{Details of the Experiments}

2.1. Casting of the Alloy and Compression Runs. Parts of pure iron, pure nickel, and pure chromium (purity of more than $99.9 \mathrm{wt} \%$ ) were melted together in order to obtain ingots of about 40 grams. For this, a high frequency induction furnace was used (CELES furnace) in inert atmosphere (300 mbars of pure Argon). After total melting and homogenization during five minutes in the liquid state, the liquid alloy was aspired in a silica tube which was dived in the levitating liquid. The solidification then occurred in this tube, which allowed obtaining a full cylinder of about four centimetres long and with a diameter of near $10 \mathrm{~mm}$.

After complete cooling the whole cylindrical ingot was extracted from the silica tube to be cut in several smaller cylindric parts. These ones were, one excepted, plastically compressed by targeting several permanent deformation rates. These compression runs were performed using an MTS $\mathrm{RF} / 150$ testing machine (experimental apparatus presented in Figure 1 and two of the obtained curves presented superposed in Figure 2).

Since no extensometer was used during the compression runs, the running deformation was calculated from the traverse movement and was not accurate because of the participation, to the recorded displacement, of the deformation of several other pieces belonging to the testing machine (platens themselves, the force-measuring cell, the testing machine traverse, etc.). The real deformation rates were assessed by measuring the initial and final heights of each cylindrical sample (no force being applied), using an electronic calliper. Three permanent deformations were finally obtained: $-3 \%,-11 \%$, and $-18 \%$.

\subsection{Preparation of the Electrodes and Impedance Spectroscopy} Runs. The as-cast sample and the three deformed samples were cut using a precision saw (Isomet 5000 of Buelher), in two parts along the cylinder axis (which is also the compression axis for the three deformed samples). A half was in each case kept for confectioning an electrode and it was

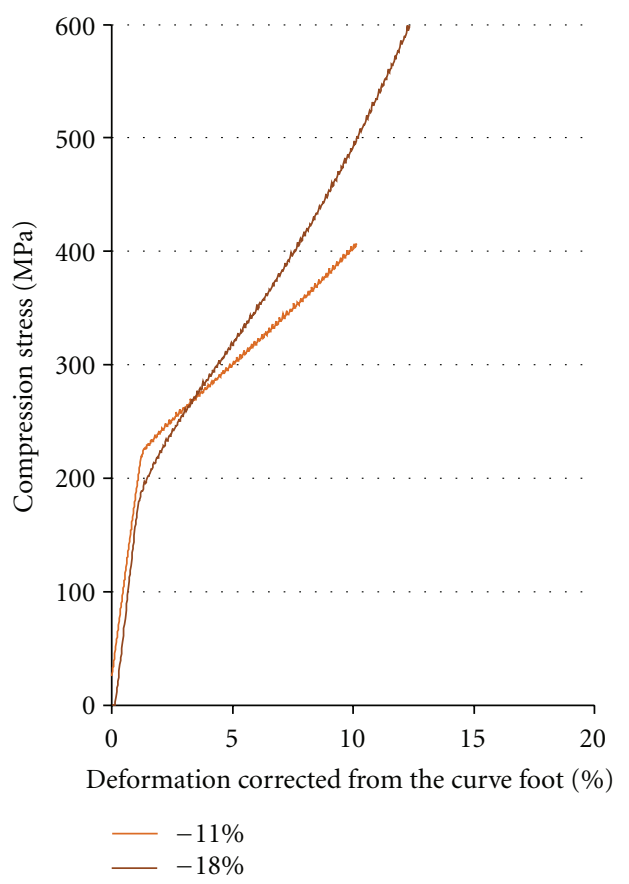

Figure 2: Two of the obtained compression curves.

embedded in a cold resin (Araldite CY230 and hardener HY 956 from ESCIL) after having been connected to a plasticcovered copper electrical wire. The electrode surface was thereafter polished with $\mathrm{SiC}$ papers up to 1200 grit.

The EIS runs were performed in a sulphuric acid aqueous solution $\left(\mathrm{H}_{2} \mathrm{SO}_{4} 2 \mathrm{~N}\right.$ using an AMETEK potentiostat, driven by the VersaStudio software). The \{three electrodes\}-cell was composed of the working electrode (the studied sample), a saturated calomel electrode (SCE) for the reference in potential, and a graphite rod for the auxiliary electrode. The applied potential $E$ varied following a sinusoidal law around the open circuit potential $\left(E_{\text {ocp }}\right)$ initially determined, between $E_{\text {ocp }}-10 \mathrm{mV}$ and $E_{\text {ocp }}+10 \mathrm{mV}$, with a frequency decreasing from $100 \mathrm{kHz}$ down to $1 \mathrm{~Hz}$. This was done 


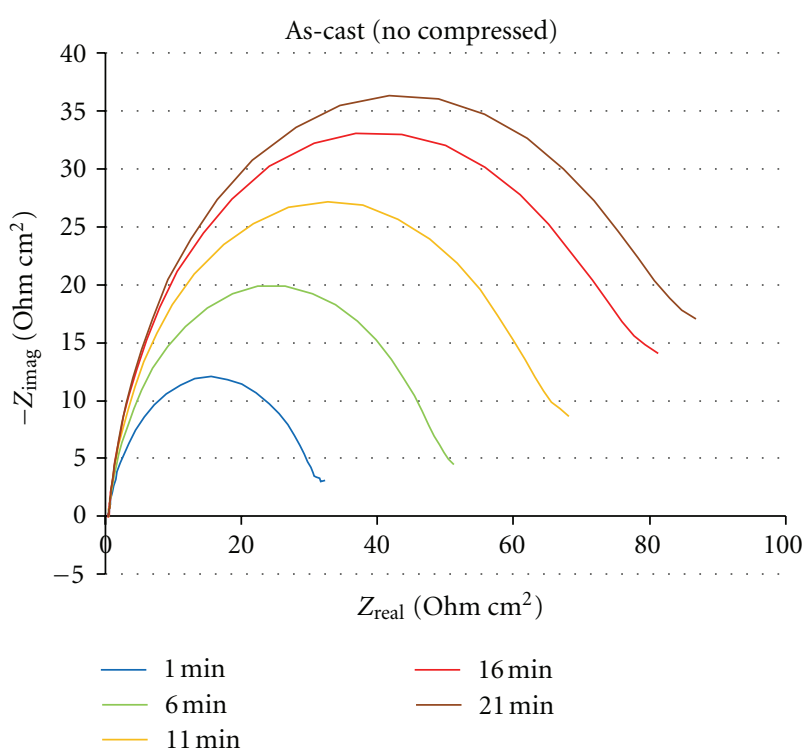

FIgURE 3: Nyquist plot of the EIS results for the five successive experiments driven for the as-cast/not-deformed sample.

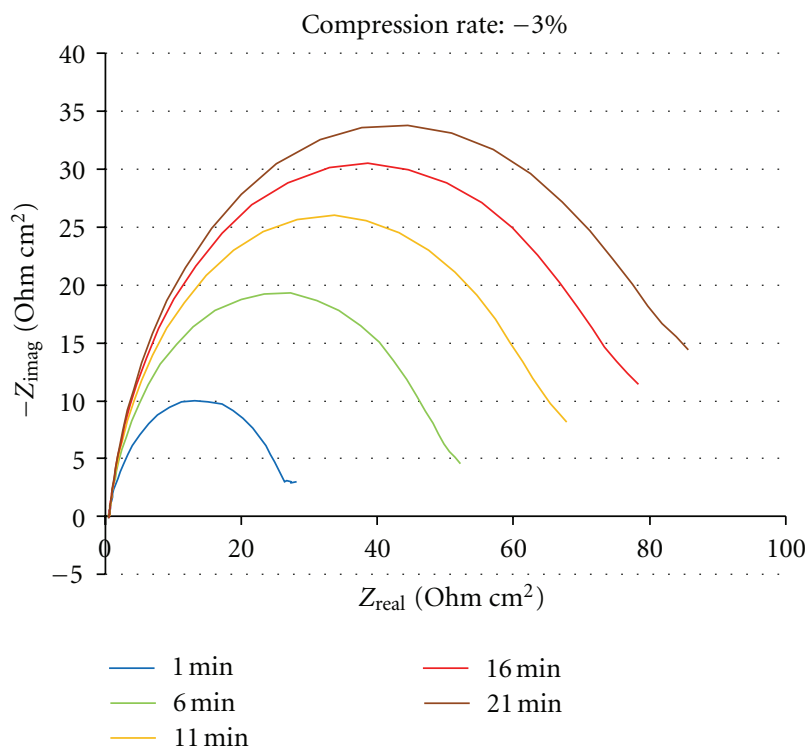

FIgURe 4: Nyquist plot of the EIS results for the five successive experiments driven for $-3 \%$ of deformation.

successively five times: at $t=1$ minute after immersion, $t=6 \mathrm{~min}, t=11 \mathrm{~min}, t=16 \mathrm{~min}$, and $t=21 \mathrm{~min}$.

\section{Results}

3.1. Nyquist Diagrams. The EIS electrochemical results for the as-cast/not deformed sample, the $\{-3 \%\}$-deformed one, the $\{-11 \%\}$-deformed one, and the $\{-18 \%\}$-deformed one are plotted in Figures 3, 4, 5, and 6, respectively. In all cases the five successive curves, recorded at $t=1,6,11,16$, and 21 minutes after immersion of the electrode, are superposed in the complex plan (opposite of the imaginary part $-Z_{\text {im }}$,

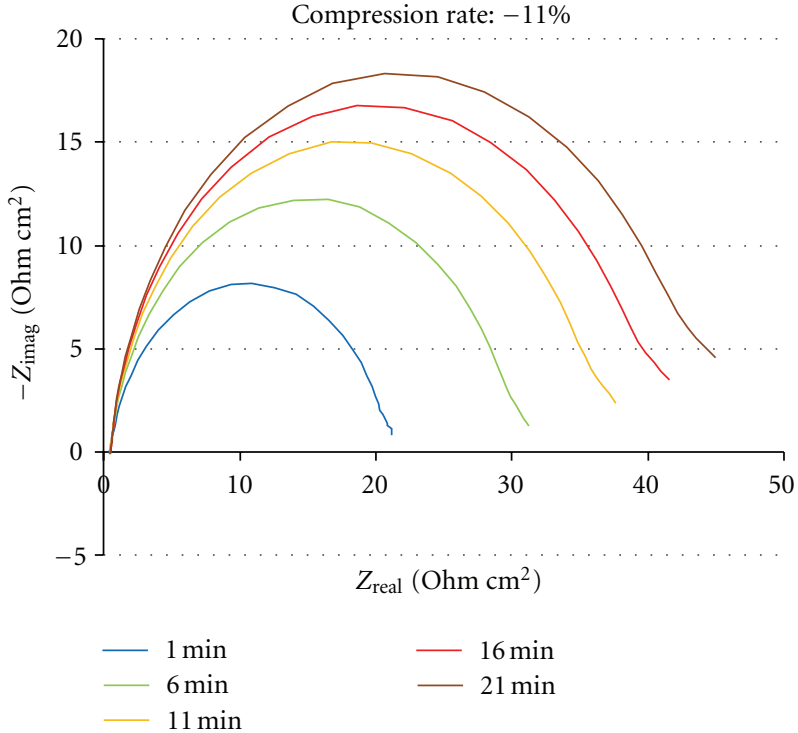

Figure 5: Nyquist plot of the EIS results for the five successive experiments driven for $-11 \%$ of deformation.

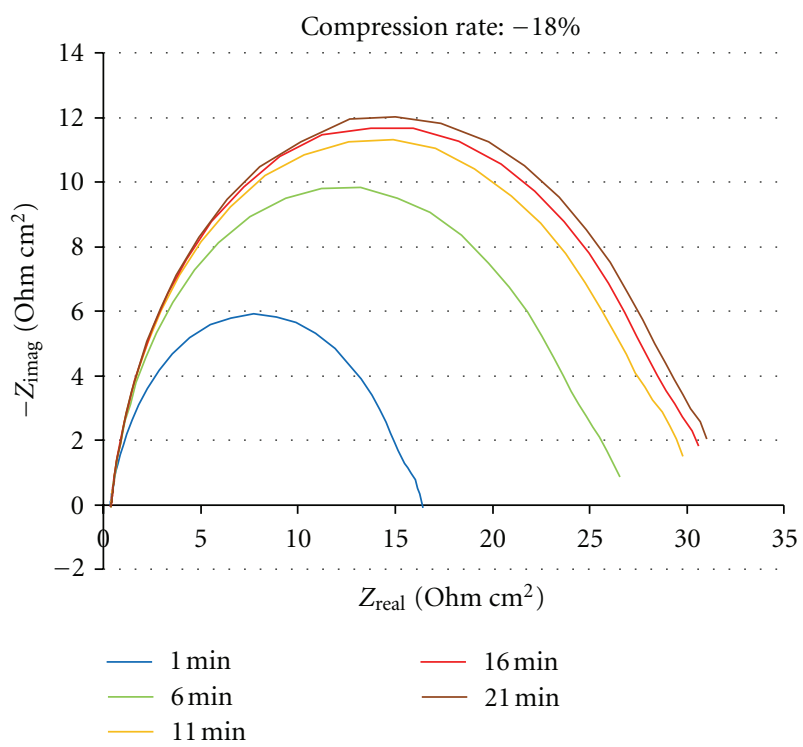

Figure 6: Nyquist plot of the EIS results for the five successive experiments driven for $-18 \%$ of deformation.

versus the real part $Z_{\text {real }}$ of the complex impedance $\left.Z(\omega)\right)$. It appears that all the Nyquist diagrams can be all considered as being almost a semicircle, despite first a radius tending to be slightly lower along the imaginary axis direction than along the real axis direction, and second a low frequency part tending to deviate from the circle shape.

By examining the evolution of the Nyquist semicircle it appears, for each deformed state, that the circle tends to increase in radius with time. The real part $\left(Z_{\text {real }}\right)$ of the impedance corresponding to the highest frequency stays almost constant at very low values (in $\Omega \times \mathrm{cm}^{2}$ : slowly increasing from 0.37 to 0.42 for the not-deformed sample, 


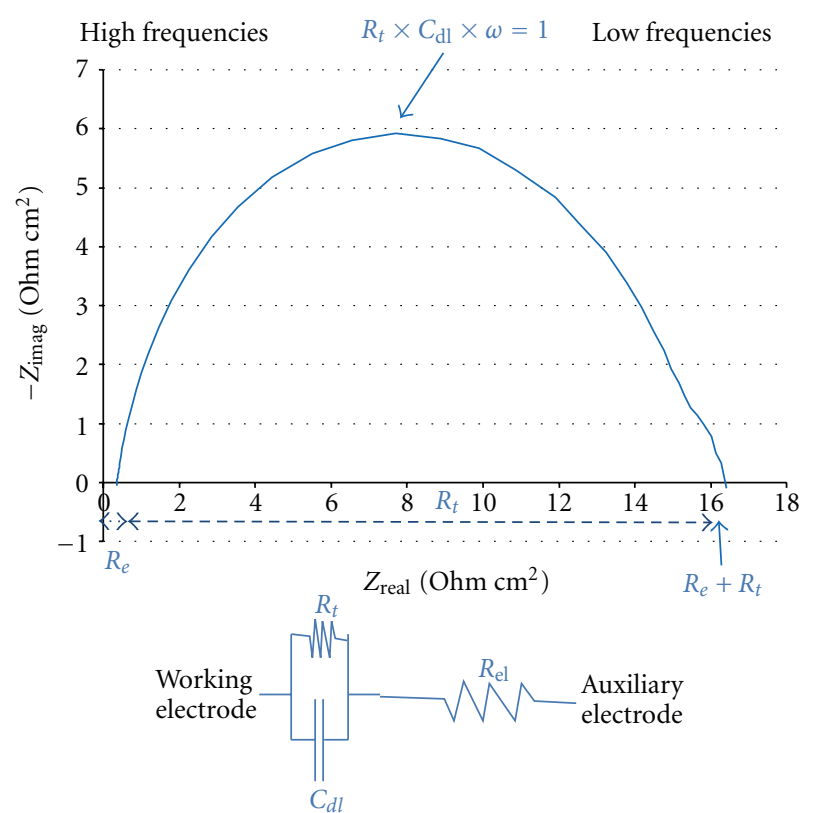

FIGURE 7: Electrochemical scheme of the $\left\{\left(R_{t} / / C_{\mathrm{dl}}\right)+R_{\mathrm{el}}\right\}$ part of the impedance model and determination of the transfer resistance $R_{t}$ and of the capacitance $C_{\mathrm{dl}}$.

from 0.45 to 0.50 for $-3 \%$ of deformation, from 0.43 to 0.49 for $-11 \%$, and from 0.34 to 0.39 for $-18 \%$ ). The abscissa of the point still belonging to the semicircle (deviating part not taken into account), which can be considered as being close to the abscissa of the theoretical point which should be obtained if the semicircle was extended to the abscissa axis, clearly increases with time but finishes to get more or less stationary after more or less fifteen minutes, the semicircles plotted for $t=16 \mathrm{~min}$ and for $t=21 \mathrm{~min}$ being very close to one another. This shows a less and less fast increase in polarization resistance, as is to say of the transfer resistance.

3.2. Exploitation of the EIS Results. Even if the Nyquist diagrams are not wholly circular (deviation in the low frequency part, probably due to a Warburg part classically found for stainless steels) the semicircle part can be exploited to extract the values of the charge transfer resistance $\left(R_{t}\right)$ and of the double layer capacitance $\left(C_{\mathrm{dl}}\right)$ (Figure 7).

The values successively obtained during the immersion for the four samples are graphically given in Figure 8 for the transfer resistance, Figure 9 for the frequency at which the summit of the semicircle was reached, and Figure 10 for the resulting value of the capacitance.

The charge transfer resistance clearly increases with time during the electrochemical counter balancing of the whole cell, but slower and slower. After twenty minutes of immersion, in the case of the not or few deformed states (ascast and $-3 \%$ ), the cell is obviously not yet at the equilibrium but the $R_{t}$ increase has significantly slowed down, while the stabilization has seemingly already occurred for the two most deformed states $(-11 \%$ and $-18 \%)$. More precisely this

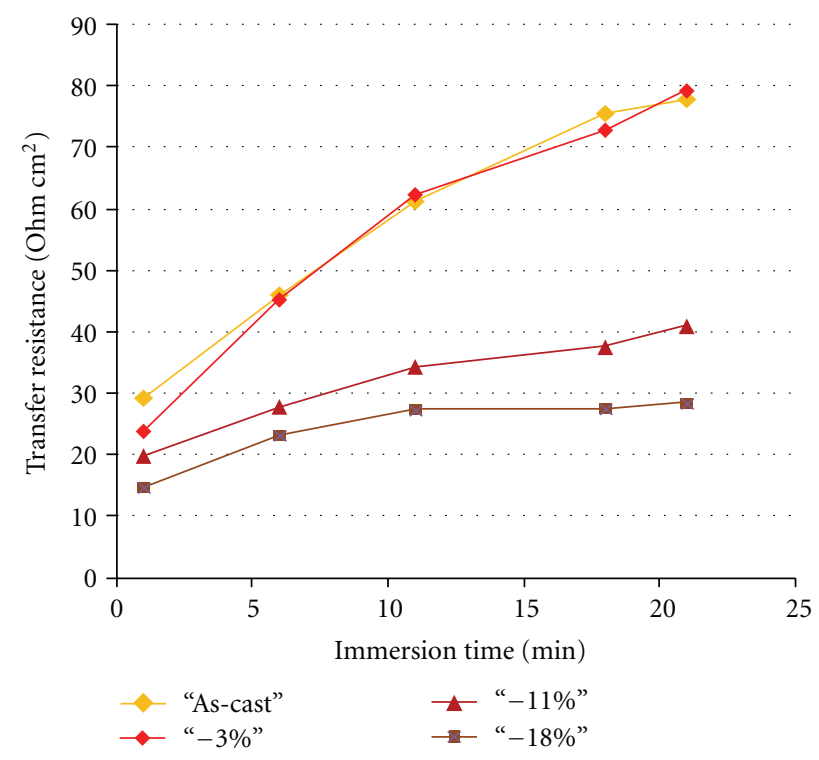

Figure 8: Evolution of the charge transfer resistance versus the immersion duration and versus the plastic deformation rate.

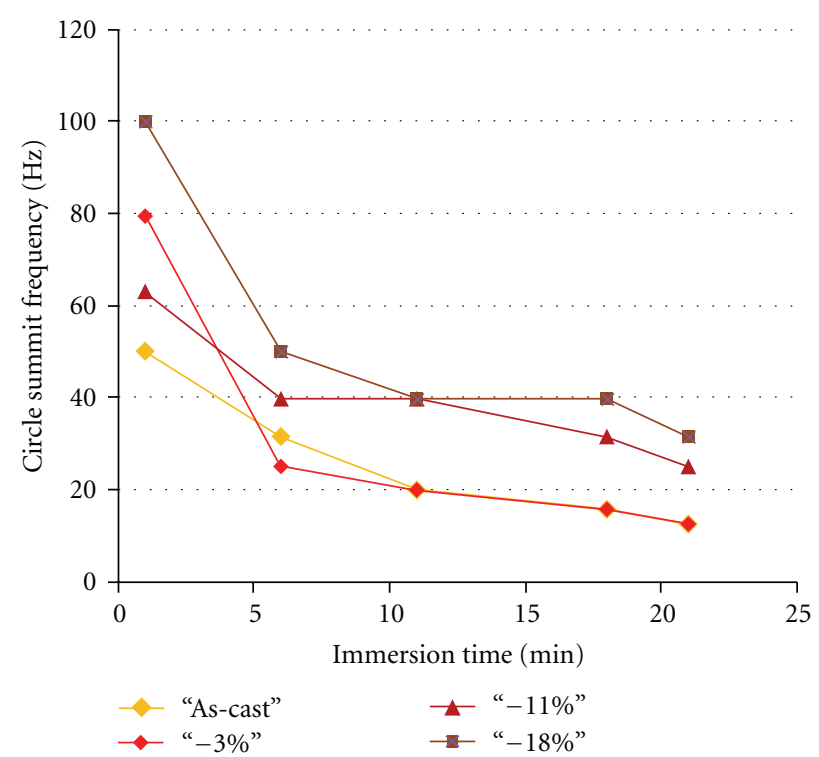

Figure 9: Evolution of the semicircle summit frequency versus the immersion duration and versus the plastic deformation rate.

was achieved after only a dozen of minutes. Furthermore, the $R_{t}$ values for these two highly deformed samples are significantly lower than the ones obtained for the two other samples, despite that the $R_{t}$ of these two last samples had not finished to increase. Obviously, the highest the deformation rate, the lowest the stabilized value of the charge transfer resistance.

The capacitance, to be calculated, needs to know the value of the pulsation $\omega$ at which the summit of the semicircle is reached, in addition to the one of the transfer resistance. The frequencies at which the semicircle summit 


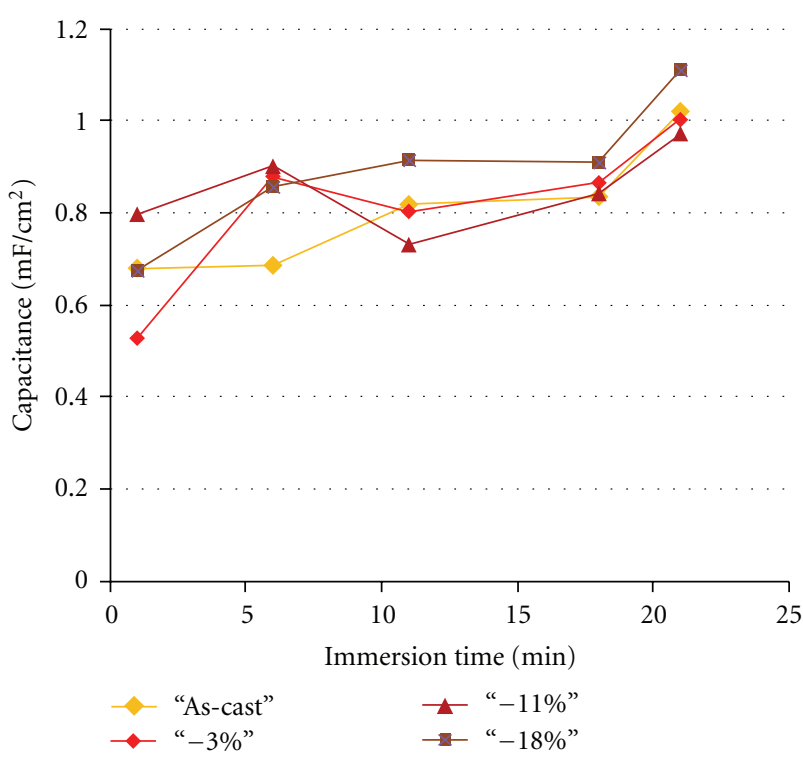

Figure 10: Evolution of the capacitance versus the immersion duration and versus the plastic deformation rate.

was obtained in the Nyquist diagrams are graphically given versus the immersion time and versus the deformation rate, in Figure 9. One can see that this frequency decreases with time and is clearly higher for the strongly deformed states than for the not or slightly deformed ones: the higher the deformation rate the higher the frequency leading to the Nyquist semicircle summit.

Able now to determine the capacitance $\left(C_{\mathrm{dl}}=1 /\left(R_{t} \times\right.\right.$ $\left.\omega)=1 /\left(2 \pi f \times R_{t}\right)\right)$, the graph representing the variation of $C_{\mathrm{dl}}$ versus time for the four deformed states can be plotted (Figure 10). The capacitance seemingly tends to increase with time but its dependence on the deformation rate is not so easy to see since the curves are not so regular as for $R_{t}$ (Figure 8 ) and $f$ (Figure 9). However it seems that $C_{\mathrm{dl}}$ tends to be higher for a higher deformation rate, as shown by the highest values obtained for the $\{-18 \%\}$-deformed state by comparison with the other states.

\section{Discussion}

The ternary alloy especially elaborated here is simple enough to allow avoiding too scattered values of the weight contents in the present elements, notably of minor elements, but it remains an interesting material of study since it can be considered as the base of many commercial steels which are often much more complex. However it presented a rather high mechanical resistance to compression which did not allow obtaining very high deformation rates despite the force capacity of the testing machine for the sample sections considered. Nevertheless the permanent deformations finally obtained $(-3 \%,-11 \%$, and $-18 \%)$ often led to significant behaviour changes in impedance spectroscopy. The $R_{t}$ resistances in the active state obtained here, are logically higher than for not-alloyed ferritic steels. This is in accordance with the rather high polarization resistances generally obtained for stainless steels with stationary methods (e.g., SternGeary). It also notably appeared that they decrease when the plastic deformation increases, showing that the corrosion resistance is affected by the plastic deformation by compression, accordingly with the largest part of observations done in the literature about the consequences, on the corrosion behaviour, of a plastic deformation whatever the deformation mode.

Additionally it was also rather interesting to see that the semicircular character of the Nyquist diagram was not affected, maybe excepted the presence of the start of another part of the diagram for the low frequencies: this part is more visible when no plastic deformation was achieved or when this one was rather low, while it almost disappeared for the most deformed states.

A higher deformation obviously induces both a decrease in $R_{t}$ and an increase in semicircle summit frequency $\mathrm{f}$ or pulsation $\omega$. The variation, with the deformation rate, of the capacitance $C_{\mathrm{dl}}$ (inverse of $R_{t} \times \omega$ ) is not so clear but it seems that this capacitance becomes higher for significant deformation rates, which is another interesting consequence of the compression deformation. Always concerning the capacitance it can be additionally noted that the values of $C_{\mathrm{dl}}$ obtained here are at the same level as for a $316 \mathrm{LN}$ steel, cold-rolled or not, when immersed in a $0.5 \mathrm{M} \mathrm{H}_{2} \mathrm{SO}_{4}$ solution [20]. On the contrary the decrease in $R_{t}$ seen here when the deformation rate increases does not correspond to what was seen for the $316 \mathrm{LN}$ steel for different amounts of cold-working [20], although the contents in Fe, Ni, and Cr were globally similar between the $316 \mathrm{LN}$ and the ternary alloy studied in the present work. This disagreement may be attributed to the presence of many other elements in the commercial steel.

\section{Conclusions}

Finally, the present study done about a Fe(bal.)-8Ni-18Cr (wt\%) ternary alloy, free of minor elements, and then allowing to simplify the role of the chemical composition, demonstrated rather clearly that the hardening of the alloy induced by the compression deformation appeared as detrimental for the corrosion resistance of the alloy in its active state since the transfer resistance, and then the polarization resistance, were lowered. This is in accordance with most of the observations earlier reported about this hardening-corrosion dependence, but obtained by stationary methods. Additionally, several interesting effects of plastic deformation were noticed for other characteristics (Nyquist semicircle shape, capacitance), which merit to be deeper investigated.

\section{Acknowledgments}

The authors wish to thank D. Veys-Renaux and C. Rapin for their advice about the EIS experiments. 


\section{References}

[1] Y. Loiko and V. I. Parkhimovich, "Effect of plastic deformation conditions on the residual stresses and (mosaic) block size in copper and in steel 45," Metallovedenie i Termicheskaya Obrabotka Metallov, vol. 165, pp. 155-165, 1965.

[2] E. Akiyama, Z. Zhang, Y. Watanabe, and K. Tsuzaki, "Effects of severe plastic deformation on the corrosion behavior of aluminum alloys," Journal of Solid State Electrochemistry, vol. 13, no. 2, pp. 277-282, 2009.

[3] G. B. Hamu, D. Eliezer, and L. Wagner, "The relation between severe plastic deformation microstructure and corrosion behavior of AZ31 magnesium alloy," Journal of Alloys and Compounds, vol. 468, no. 1-2, pp. 222-229, 2009.

[4] W. Y. Guo, J. Sun, and J. S. Wu, "Effect of deformation on corrosion behavior of Ti-23Nb-0.7Ta-2Zr-O alloy," Materials Characterization, vol. 60, no. 3, pp. 173-177, 2009.

[5] B. Mazza, P. Pedeferri, D. Sinigaglia, U. Della Sala, and L. Lazzari, "Contribution to the knowledge of the relationship between the electrochemical and corrosion behaviour and the structure of metallic materials subjected to cold plastic deformation," Werkstoffe und Korrosion, vol. 25, no. 4, pp. 239253, 1974.

[6] B. Mazza, P. Pedeferri, D. Sinigaglia et al., "Relationship between the electrochemical and corrosion behavior and the structure of stainless steels subjected to cold plastic deformation," Journal of the Electrochemical Society, vol. 123, no. 8, pp. 1157-1163, 1976.

[7] V. I. Storonskii, "Effect of cold-working on corrosion and the mechanical properties of steel 20 in inhibited solutions of hydrochloric acid," Teploenergetika, vol. 33, no. 11, pp. 615616, 1986.

[8] V. A. C. Haanappel and M. F. Stroosnijder, "Influence of mechanical deformation on the corrosion behavior of AISI 304 stainless steel obtained from cooking utensils," Corrosion, vol. 57, no. 6, pp. 557-565, 2001.

[9] P. Berthod, "Effect of a plastic deformation on the electrochemical behaviors and the corrosion rates of pure iron, nickel and copper in a molar solution of sulfuric acid," Materials Science, vol. 5, no. 3, pp. 161-167, 2009.

[10] D. Landolt, Traité Des MatéRiaux-N $N^{\circ} 12$ Corrosion Et Chimie De Surface Des MéTaux, Presses Polytechniques et Universitaires Romandes, Lausanne, Switzerland, 1997.

[11] M. Sanchez, H. Mahmoud, and M. C. Alonso, "Electrochemical response of natural and induced passivation of high strength duplex stainless steels in alkaline media," Journal of Solid State Electrochemistry, vol. 16, no. 3, pp. 1193-1202, 2012.

[12] J. J. Shi and W. Sun, "Equivalent circuits fitting of electrochemical impedance spectroscopy for corrosion of reinforcing steel in concrete," Fushi Kexue Yu Fanghu Jishu, vol. 23, no. 5, p. 387-392, 2011.

[13] X. Li, Y. Wang, C. Du, and B. Yan, "Corrosion behaviors of amorphous and nanocrystalline fe-based alloys in $\mathrm{NaCl}$ solution," Journal of Nanoscience and Nanotechnology, vol. 10, no. 11, pp. 7226-7230, 2010.

[14] A. Hemmasian-Ettefagh, M. Amiri, and C. Dehghanian, "Corrosion inhibition of carbon steel in cooling water," Materials Performance, vol. 49, no. 3, pp. 60-65, 2010.

[15] Y. Ma, Y. Li, and F. Wang, "Corrosion of low carbon steel in atmospheric environments of different chloride content," Corrosion Science, vol. 51, no. 5, pp. 997-1006, 2009.

[16] M. M. T. Luque, J. J. O. Florez, and H. del Lujan, "Resistencia a la corrosión de recubrimientos electroquímicos de cromo y zinc mediante EIE," Ingenieria Y Desarrollo, vol. 29, no. 2, p. $170,2011$.

[17] B. Rosborg, T. Kosec, A. Kranjc, J. Pan, and A. Legat, "Electrochemical impedance spectroscopy of pure copper exposed in bentonite under oxic conditions," Electrochimica Acta, vol. 56, p. 7862, 2011.

[18] J. Ma, J. Wen, X. Lu, and Y. Li, "Electrochemical impedance spectroscopy of aluminum alloy anode during corrosion process," Fushi Yu Fanghu, vol. 30, no. 6, pp. 373-376, 2009.

[19] D. Šatović, L. V. Žulj, V. Desnica, S. Fazinić, and S. Martinez, "Corrosion evaluation and surface characterization of the corrosion product layer formed on $\mathrm{Cu}-6 \mathrm{Sn}$ bronze in aqueous $\mathrm{Na}_{2} \mathrm{SO}_{4}$ solution," Corrosion Science, vol. 51, no. 8, pp. 1596$1603,2009$.

[20] M. G. Pujar, N. Parvathavarthini, and R. K. Dayal, "Some aspects of corrosion and film formation of austenitic stainless steel type 316LN using electrochemical impedance spectroscopy (EIS)," Journal of Materials Science, vol. 42, no. 12, pp. 4535-4544, 2007. 

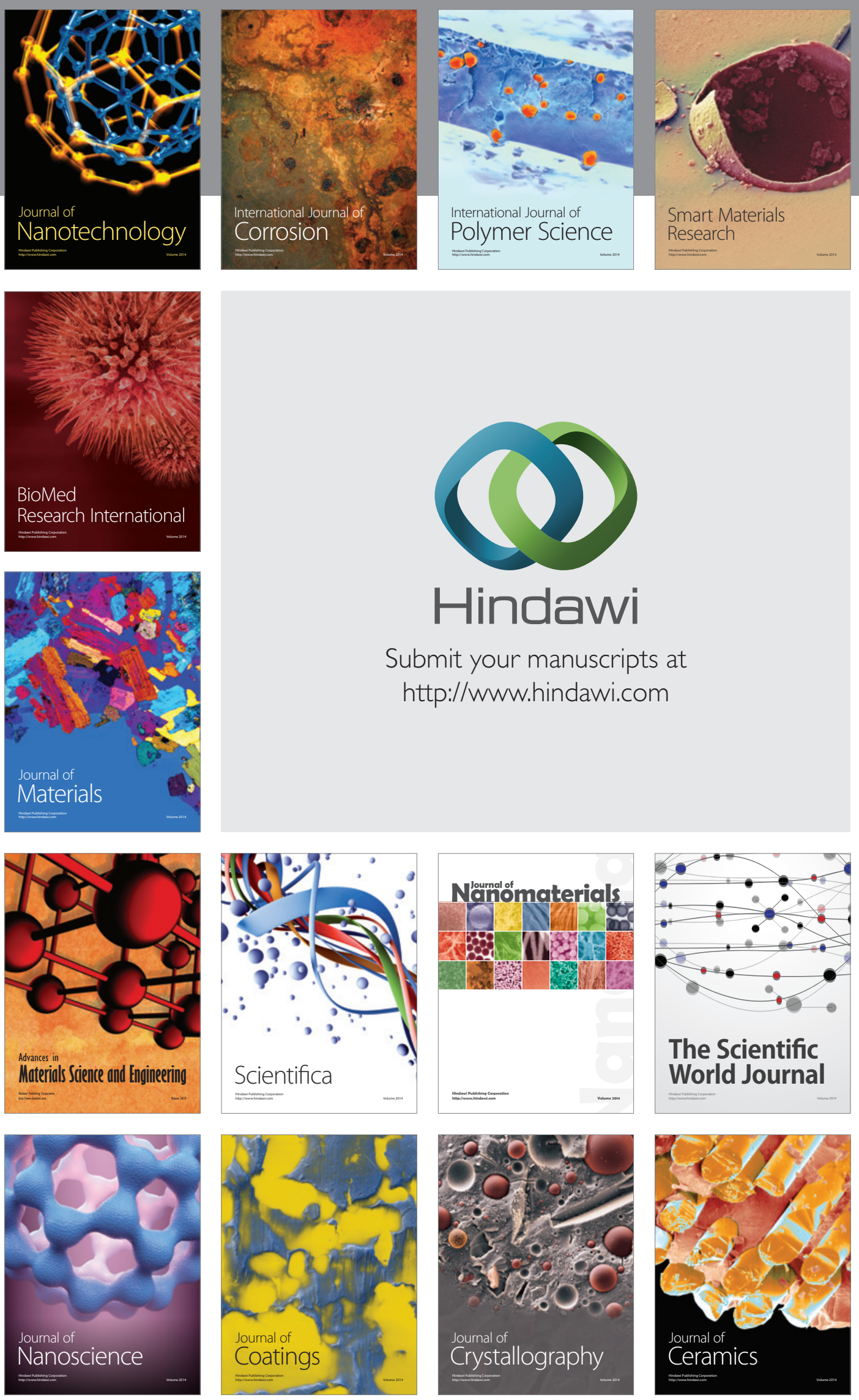

The Scientific World Journal

Submit your manuscripts at

http://www.hindawi.com

\section{World Journal}

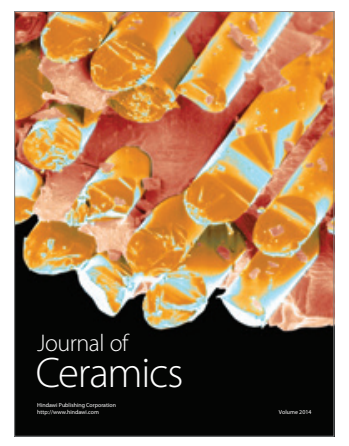

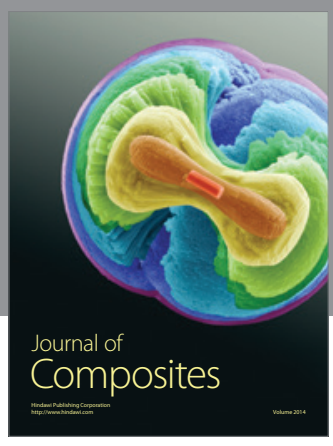
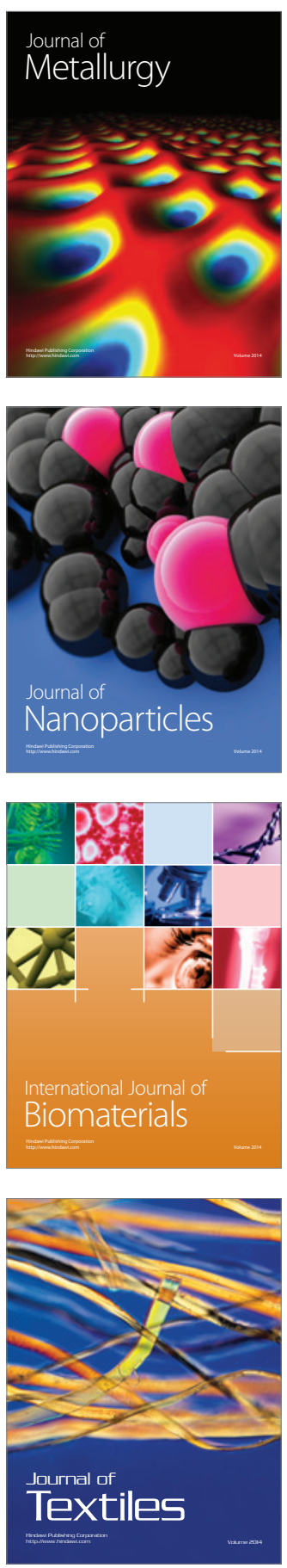